\title{
Laboratory Review of Foodborne Disease Investigations in Washington State 2007-2017
}

\author{
Jennifer L. Swoveland, ${ }^{1}$ Laurie K. Stewart, ${ }^{2}$ Mary Kaye Eckmann, ${ }^{1}$ Raymond Gee, \\ Krisandra J. Allen, ${ }^{2}$ Calley M. Vandegrift, ${ }^{1}$ Gina Olson, ${ }^{1}$ Mi-Gyeong Kang, ${ }^{1}$ Michael L. Tran, \\ Elizabeth Melius, ${ }^{2}$ Brian Hiatt, ${ }^{1}$ Romesh K. Gautom, ${ }^{1}$ and Ailyn C. Perez-Osorio ${ }^{1}$
}

\begin{abstract}
The Washington State Department of Health Public Health Laboratories (WAPHL) has tested 11,501 samples between 2007 and 2017 for a foodborne disease using a combination of identification, serotyping, and subtyping tools. During this period there were 8037 total clinical and environmental samples tested by pulsed-field gel electrophoresis (PFGE), including 512 foodborne disease clusters and 2176 PFGE patterns of Salmonella enterica subsp. enterica. There were 2446 Shiga toxin-producing Escherichia coli samples tested by PFGE, which included 158 foodborne disease clusters and 1174 PFGE patterns. There were 332 samples of Listeria monocytogenes tested by PFGE, including 35 foodborne disease clusters and 104 PFGE patterns. Sources linked to outbreaks included raw chicken, unpasteurized dairy products, various produce types, and undercooked beef among others. As next-generation sequencing (NGS) replaces PFGE, the impact of this transition is expected to be significant given the enhanced cluster detection power NGS brings. The measures presented here will be a reference baseline in future years.
\end{abstract}

Keywords: Washington State, PFGE, Salmonella, Listeria, foodborne illness and disease, PulseNet

\section{Introduction}

A PPROXIMATELY 3000 NOTIFIABLE enteric foodborne illnesses are reported annually in Washington (WA) State, with 1-10 associated deaths (CDC, 2015a). The foodborne disease category is a leading cause of infectious illnesses in WA. Clinical laboratories in WA are required to submit specimens or isolates from patients diagnosed with listeriosis, salmonellosis, shigellosis, vibriosis, or infection with Shiga toxin Department of Health-producing Escherichia coli (STEC) to the Washington State Public Health Laboratories (WAPHL). Submissions are characterized to confirm the initial identification and some isolates are further serotyped and subtyped.

The PulseNet program is a national laboratory network that allows participating laboratories to link molecular characteristics of bacterial isolates from foodborne illness cases to detect outbreaks (Swaminathan et al., 2001). WAPHL was among the first four state PHLs to join the Centers for Disease Control and Prevention (CDC)-sponsored PulseNet program in 1996 (Stephenson, 1997; CDC, 2016b) and has continued its key role as the Western PulseNet Region Area Laboratory for $>20$ years. PulseNet relies on the use of standardized pulsedfield gel electrophoresis (PFGE) equipment, methodology, and analysis tools that link data across participating laboratories to detect clusters.

The primary source of infection with Listeria monocytogenes, STEC, Salmonella enterica, Campylobacter jejuni, Yersinia spp., Vibrio cholerae, or Vibrio parahaemolyticus is undercooked or adulterated food. Although listeriosis and STEC infections represent a small proportion of all foodborne illnesses, outcomes can be severe so each case is carefully investigated. Listeriosis occurs primarily in individuals with immunosuppression, pregnant women, neonates, and the elderly as invasive infection that can carry a mortality rate of at least 16\% (Farber and Peterkin, 1991; Barton Behravesh et al., 2011; CDC, 2016a). STEC infections can also be severe because of the risk of developing hemolytic uremic syndrome that carries a high mortality rate particularly, for children

\footnotetext{
${ }^{1}$ Public Health Laboratories, Washington State Department of Health, Shoreline, Washington.

${ }^{2}$ Communicable Disease Epidemiology, Washington State Department of Health, Shoreline, Washington.
}

(C) Jennifer L. Swoveland et al. 2019; Published by Mary Ann Liebert, Inc. This Open Access article is distributed under the terms of the Creative Commons License (http://creativecommons.org/licenses/by/4.0), which permits unrestricted use, distribution, and reproduction in any medium, provided the original work is properly cited. 
younger than 4 years (Barton Behravesh et al., 2011). Along with listeriosis, salmonellosis causes the most deaths because of a foodborne disease in WA, despite a lower case fatality rate. This is because salmonellosis is among the most common bacterial foodborne infections, second only to campylobacteriosis (CDC, 2015b; Laufer et al., 2015).

The aim of this publication was to summarize the work that WAPHL has carried out over the past 11 years (2007-2017) in the area of foodborne disease investigations. The transition as next-generation sequencing (NGS) replaces PFGE is expected to have a significant impact given the enhanced cluster detection power because of the increase in resolution of NGS. In addition, the use of culture independent diagnostic testing (CIDT) and its impacts on the need for isolates are briefly addressed. The measures presented here will be a baseline for reference in future years. Although WAPHL has applied PFGE to organisms other than those already mentioned, this summary will focus on only these organisms and the work WAPHL has performed for WA residents.

\section{Materials and Methods}

\section{Bacteria isolation, identification, and subtyping}

STEC were isolated and identified using MacConkey with sorbitol (SMAC), tellurite, and cefixime (CT-SMAC), and Rainbow agar with novobiocin and tellurite. Specimens not already in Gram Negative (GN) broth were enriched by inoculating GN broth. All specimens were initially screened for functional Shiga toxin utilizing a lateral flow enzyme immunoassay (EIA) test (Meridian ImmunoCard STAT! ${ }^{\circledR}$ enterohemorrhagic E. coli [EHEC] or Alere SHIGA TOXIN QUIK $C H E K^{\mathrm{TM}}$ ) which detects and differentiates Shiga toxin 1 and Shiga toxin 2 (Staples et al., 2017). Isolates were tested for Shiga toxin production and were confirmed biochemically. If the isolate was Shiga toxin positive and biochemically resembled $E$. coli, the isolate was serotyped using $E$. coli OK antisera or antibody-coated latex beads. Turnaround time for STEC isolation and confirmation was 4-7 business days. These isolates were routinely tested by PFGE.

Salmonella were isolated and identified using MacConkey (MAC), Hektoen Enteric (HE) agar, Salmonella-Snigella (SS) agar, and brilliant green agar. Stool were inoculated into selenite broth and tetrathionate broth as a selective enrichment for better recovery of Salmonella spp. Isolates resembling Salmonella were confirmed using biochemicals. From 2007 to 2012, Salmonella isolates were serotyped utilizing Salmonella antisera to determine $\mathrm{O}$ and $\mathrm{H}$ antigens. From 2012 to 2017, molecular techniques (Illumina xMAP Salmonella serotyping assay) were used to serotype Salmonella isolates, supplemented with Salmonella antisera (Dunbar et al., 2015). Turnaround time for Salmonella isolation and confirmation was 4-7 business days. All Salmonella isolates were routinely tested by PFGE.

Listeria from clinical specimens were identified using blood agar plates (BAP), brain-heart infusion (BHI) broth agar slant or a heart infusion agar (HIA) slant, and MAC to look for purity, hemolysis (BAP), and inhibited growth (MAC). A single colony was picked from the BAP to inoculate a set of biochemicals to confirm L. monocytogenes. If the results were not typical for L. monocytogenes, then hippurate and CAMP tests were performed to help with the identification. Turnaround time for Listeria identification was 3-5 business days.
Listeria isolates were routinely tested by PFGE for subtyping and a BHI/HIA was referred to the CDC for further studies.

Listeria from food samples and environmental samples were isolated and identified using a modified Food and Drug Administration Bacteriological Analytical Manual procedure for detecting Listeria in food (FDA, 2017).

Media and test reagents for Salmonella, E. coli, and Listeria isolation and identification were purchased commercially with a few exceptions. Antisera were purchased from Difco, Denka Seiken, or SSI Diagnostica. Media and most biochemicals were purchased from Remel and Hardy Diagnostics. The antibody-coated latex beads were purchased from Pro-Lab for E. coli Non-O157 (E. coli Non-O157 Latex Test Reagent Kit) and from Remel for E. coli O157 (Remel RIM E. coli O157:H7 Latex test). Carbohydrate biochemicals and nutrient broths were made in-house at the WAPHL. All manufactured media were used following the manufacturer guidelines. All WAPHL in-house media use followed the Enterics and Special Bacteriology Reference Units laboratory procedure manuals and microbiology reference books (Holt, 1994; Weyant, 1996; MacFaddin, 2000; de la Maza, 2004; Garcia and Isenberg, 2010; Jorgensen, 2015).

\section{PFGE subtyping}

PFGE subtyping was carried out using PulseNet protocols for running and analyzing PFGE gels (Graves and Swaminathan, 2001; Ribot et al., 2001, 2006; Swaminathan et al., 2001; Parsons et al., 2007). Turnaround time for PFGE was 4 business days. PFGE patterns were compared with other patterns both in the WA database and in the national CDC PulseNet database using BioNumerics software. Any pattern matches were further assessed to determine if they should be considered a cluster and clusters were reported to an epidemiologist.

\section{Cluster definition}

For this publication a cluster identified by WAPHL is defined as two or more cases with matching PFGE patterns and similar illness onset date (within $60 \mathrm{~d}$ ). Other supportive information for defining a cluster is similar geographic distribution or similar demographics, especially for a common PFGE pattern (Bender et al., 2001; Barrett et al., 2006; Tauxe, 2006). A foodborne disease outbreak is defined as two or more people with the same illness from a shared identified food or drink. Outbreaks vary in size and are classified depending on the spread of disease as local, multicounty, or multistate (CDC, 2015b). Ill people from the same household are not counted as a cluster.

\section{Results}

Between 2007 and 2017 WA received a total of 33,079 notifiable bacterial disease case reports for foodborne illnesses. During this period WAPHL received a total of 12,885 human enteric isolates of which 11,134 received PFGE characterization (Fig. 1). Of human enteric reports (confirmed, probable, and suspect cases), $51 \%$ were attributed to campylobacteriosis, $27 \%$ to salmonellosis, $9 \%$ to STEC, and $10 \%$ to other enteric illnesses including listeriosis, vibriosis, cholera, and shigellosis. 


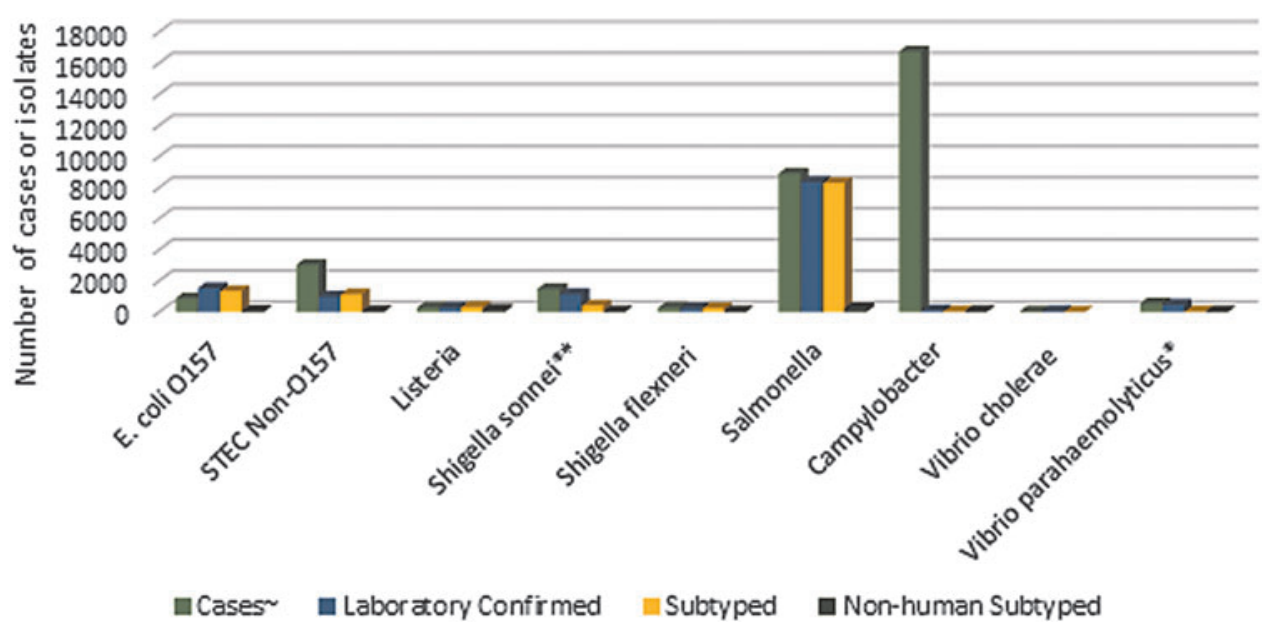

FIG. 1. Total number of case reports received, laboratory confirmed isolates, and subtyped isolates by PFGE stratified per pathogen. $\sim$ Cases include confirmed, probable, and suspect. *Vibriosis cases. $* *$ Shigellosis cases. PFGE, pulsed-field gel electrophoresis.

There were 8759 salmonellosis and typhoid fever cases (confirmed, probable, and suspect) reported during the period and 7829 Salmonella isolates were subtyped at WAPHL (Table 1). Among the S. enterica subsp. enterica isolates tested, the most frequent serotypes identified, in order, were Enteritidis, Typhimurium, I 4,[5],12:i:-, Heidelberg, and Newport. Table 2 presents the most common serotypes reported in WA. Less common serotypes detected in WA are reported elsewhere (Washington State Department of Health). Serotypes Enteritidis and Typhimurium topped all serotypes for each year during 2007-2017, except for 2015 when a large outbreak of serotype I 4,5,12:i:- associated with roasted whole hogs occurred (Kawakami et al., 2016).

Within serotypes Enteritidis, Typhimurium, and I 4,5,12:i:there were 110, 287, and 97 distinct PFGE patterns, respectively (Table 1). For all Salmonella serotypes there was an average of 45 Salmonella PFGE clusters per year (Table 1). Salmonella Enteritidis was responsible for multiple confirmed outbreaks linked to travel to Mexico, dining at local restaurants, or consuming poultry (Table 3 ). One outbreak linked to alfalfa sprouts and spicy sprouts sickened 25 people, 10 residing in WA. Three people were hospitalized and the investigation was closed on July 6, 2011, after the company voluntarily recalled the product (CDC, 2011). Salmonella Typhimurium outbreak vehicles included chicks, peanut butter, alfalfa sprouts, hedgehogs, a teaching laboratory exposure, and restaurants. An outbreak as a result of rotisserie chicken salad contaminated with Salmonella Typhimurium was identified in 2016.

Food vehicles leading to recurrent outbreaks associated with other Salmonella serotypes included pot pie and pig roast linked to Salmonella I 4,[5],12:i:- (Kawakami et al., 2016) and frozen raw chicken linked to Salmonella Heidelberg (Green et al., 2018). Sources linked to multiple Salmonella serotypes included live chicks, pet reptiles, and multiple restaurants. Produce vehicles linked to salmonellosis outbreaks included mangoes, green onions, peppers, and pistachios. In 2015 there were two outbreaks resulting from exposure to peanut butter (Salmonella Newport) and spicy tuna rolls [Salmonella Paratyphi B L(+) Tartrate(+)]. One Salmonella Saintpaul outbreak in 43 U.S. states and Canada linked to jalapeno and serrano peppers, and possibly to raw tomatoes, affected 1442 people with 2 deaths (CDC, 2008b) (Table 3). In 2007 a WA outbreak involving 12 illnesses was linked to the use of an improperly cleaned food slicer contaminated with Salmonella Seftenberg. During the 20072017 period there were a total of 23 deaths associated with salmonellosis in WA.

The total number of confirmed, probable, and suspect cases as a result of STEC reported between 2007 and 2017 was 2525 , of which 1373 cases were attributed to E. coli $\mathrm{O} 157$, 293 cases were attributed to E. coli O26, and 691 were attributed to other E. coli serotypes (not shown). Among E. coli O157 isolates there were 1398 PFGE patterns and 129 PFGE clusters (Table 1). Outbreaks were linked to consuming undercooked beef $(2007,2009)$, cookie dough (2009), or unpasteurized milk (Table 3); in addition, outbreaks occurred at day care centers, at petting zoos, or owing of contact with grazing animals. There were 10 STEC-related fatalities reported during this period (Table 1). For E. coli non-O157 there were 776 PFGE patterns and 29 PFGE clusters (Table 1), which included outbreaks because of raw sprouts and uncooked flour. In addition, lettuce, leafy greens, kale, and spinach were also found to be STEC vehicles (Table 3). Culture submissions for STEC testing decreased and stools and broths submitted to WAPHL for testing increased since 2012 (Fig. 2).

There were 249 confirmed, probable, and suspect $L$. monocytogenes cases reported between 2007 and 2017 including 18 deaths (case fatality rate of $7.5 \%$ ). A total of 218 Listeria human and 114 nonhuman isolates were tested by PFGE with 104 PFGE patterns and 35 PFGE clusters observed during this period (Table 1). Outbreaks were associated with dairy products including raw milk, Mexican style soft cheeses, ice cream, and caramel apples (Table 3) as well as produce (lettuce, kale, cantaloupe, and onions).

\section{Discussion}

Salmonellosis has several characteristics that make control difficult (Ailes et al., 2008). It occurs naturally in cattle, poultry, and eggs and is not considered an adulterant in raw 


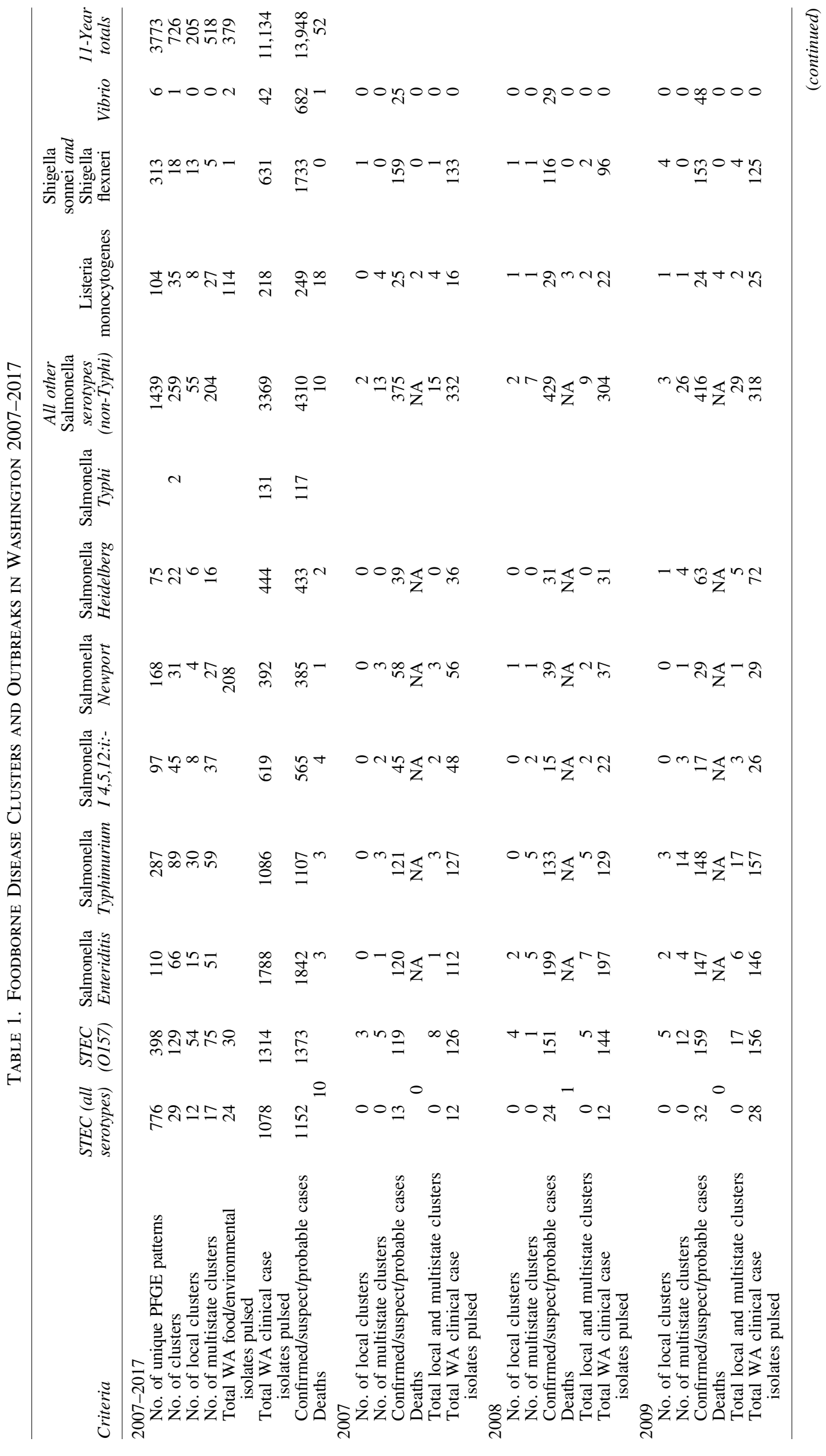




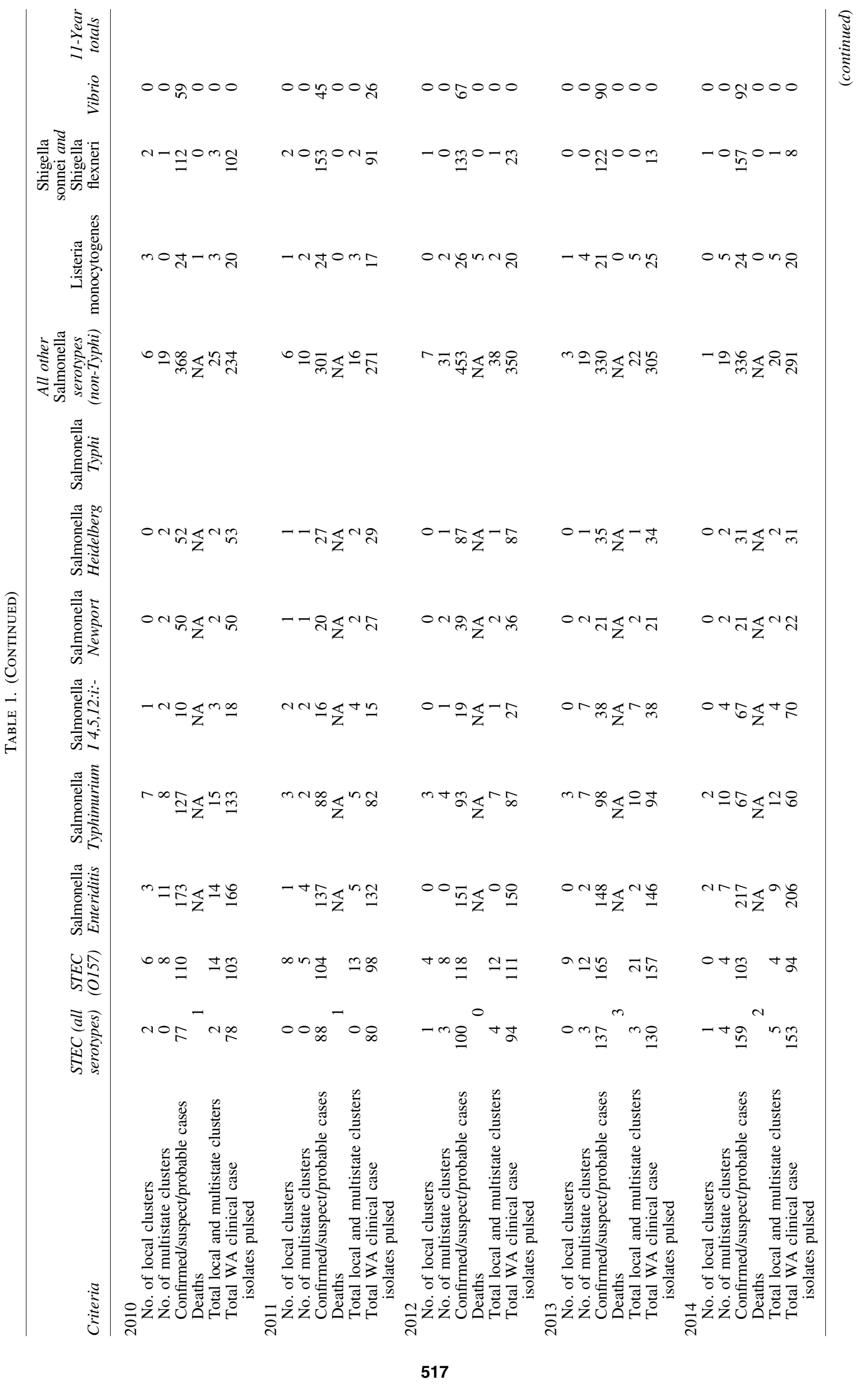




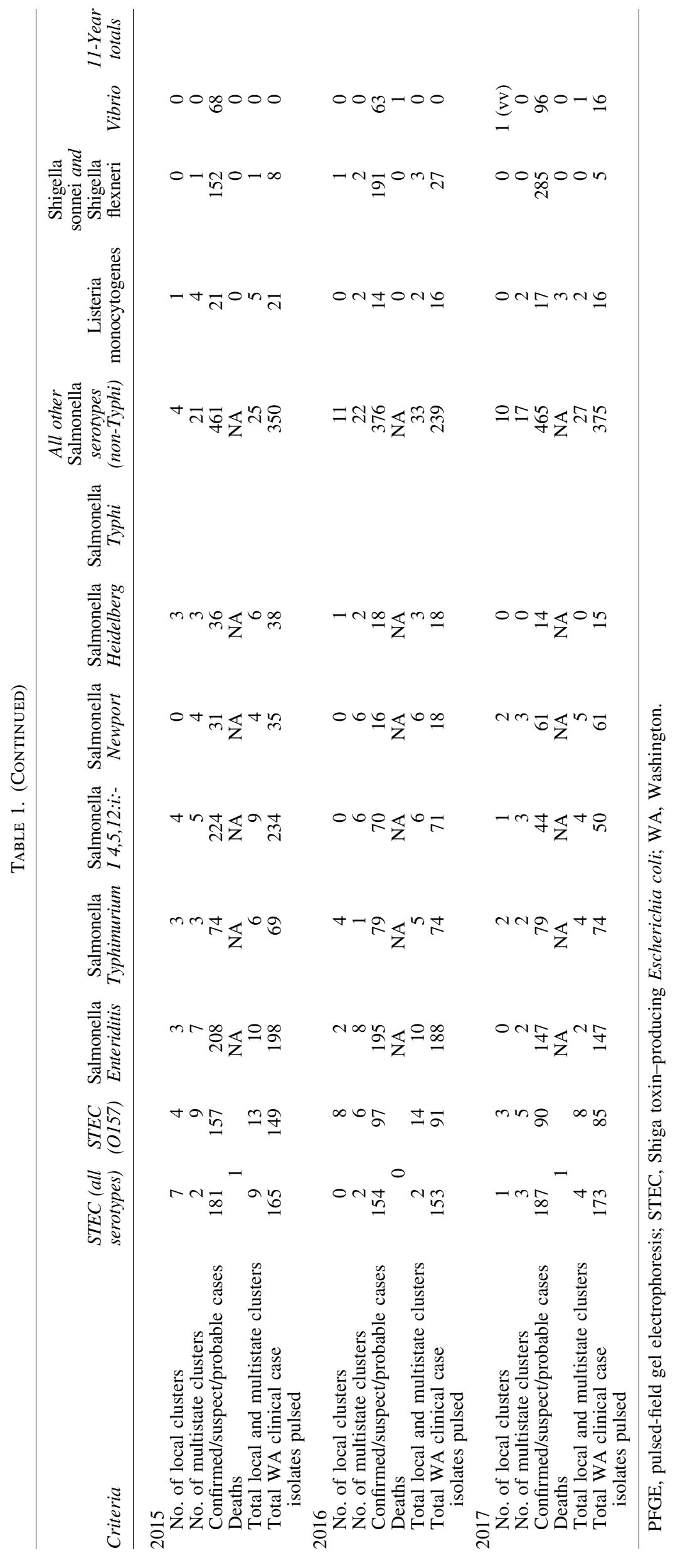


Table 2. Predominant Salmonella Serovars Detected in Washington State During 2007-2017

\begin{tabular}{|c|c|c|c|c|c|c|c|c|c|c|c|c|}
\hline Serotype & 2007 & 2008 & 2009 & 2010 & 2011 & 2012 & 2013 & 2014 & 2015 & 2016 & 2017 & Total \\
\hline Agona & 13 & 25 & 9 & 15 & 18 & 9 & 9 & 6 & 11 & 4 & 7 & 126 \\
\hline Anatum & 3 & 9 & 7 & 7 & 7 & 8 & 3 & 8 & 2 & 3 & 5 & 62 \\
\hline Bareilly & 1 & 3 & 2 & 2 & 2 & 9 & 2 & 1 & 0 & 1 & 6 & 29 \\
\hline Berta & 0 & 0 & 0 & 3 & 3 & 4 & 3 & 2 & 6 & 6 & 2 & 29 \\
\hline Braenderup & 9 & 14 & 14 & 11 & 17 & 22 & 9 & 8 & 20 & 19 & 12 & 155 \\
\hline Brandenburg & 4 & 1 & 0 & 5 & 8 & 4 & 11 & 2 & 5 & 11 & 3 & 54 \\
\hline Chester & 2 & 3 & 1 & 10 & 0 & 1 & 2 & 2 & 1 & 2 & 3 & 27 \\
\hline Dublin & 6 & 2 & 4 & 8 & 5 & 2 & 3 & 8 & 6 & 8 & 5 & 57 \\
\hline Enteritidis & 120 & 199 & 147 & 173 & 137 & 151 & 148 & 217 & 208 & 195 & 147 & 1842 \\
\hline Hadar & 7 & 9 & 15 & 6 & 12 & 13 & 6 & 8 & 14 & 3 & 7 & 100 \\
\hline Havana & 2 & 1 & 2 & 3 & 1 & 1 & 1 & 3 & 6 & 0 & 1 & 21 \\
\hline Heidelberg & 39 & 31 & 63 & 52 & 27 & 87 & 35 & 31 & 36 & 18 & 14 & 433 \\
\hline I 4,12:i:- & 8 & 6 & 8 & 0 & 0 & 1 & 0 & 2 & 10 & 0 & 5 & 40 \\
\hline I 4,5,12:b:- & 0 & 0 & 0 & 0 & 0 & 2 & 2 & 13 & 15 & 8 & 11 & 51 \\
\hline I 4,5,12:i:- & 46 & 17 & 19 & 10 & 13 & 28 & 38 & 67 & 224 & 70 & 44 & 576 \\
\hline Infantis & 10 & 11 & 15 & 18 & 11 & 22 & 13 & 19 & 18 & 24 & 28 & 189 \\
\hline Javiana & 10 & 10 & 9 & 11 & 11 & 8 & 7 & 7 & 13 & 17 & 18 & 121 \\
\hline Kentucky & 1 & 3 & 3 & 3 & 2 & 2 & 7 & 2 & 2 & 3 & 1 & 29 \\
\hline Litchfield & 1 & 16 & 4 & 4 & 2 & 1 & 2 & 3 & 0 & 4 & 0 & 37 \\
\hline Mbandaka & 7 & 6 & 5 & 10 & 6 & 6 & 6 & 4 & 5 & 4 & 4 & 63 \\
\hline Montevideo & 32 & 34 & 44 & 29 & 13 & 19 & 13 & 17 & 12 & 14 & 16 & 243 \\
\hline Muenchen & 12 & 6 & 12 & 12 & 7 & 8 & 16 & 16 & 10 & 22 & 20 & 141 \\
\hline Newport & 58 & 39 & 29 & 50 & 20 & 39 & 21 & 21 & 31 & 16 & 61 & 385 \\
\hline Oranienburg & 12 & 10 & 21 & 14 & 10 & 11 & 18 & 16 & 15 & 28 & 19 & 174 \\
\hline Panama & 3 & 3 & 5 & 5 & 10 & 4 & 5 & 5 & 6 & 4 & 2 & 52 \\
\hline Paratyphi A & 3 & 2 & 3 & 1 & 3 & 10 & 12 & 7 & 4 & 7 & 4 & 56 \\
\hline Paratyphi B & 2 & 1 & 1 & 1 & 2 & 1 & 1 & 1 & 1 & 0 & 0 & 11 \\
\hline Paratyphi B var. L(+) tartrate $(+)$ & 17 & 19 & 18 & 14 & 11 & 8 & 14 & 5 & 8 & 10 & 28 & 152 \\
\hline Poona & 5 & 19 & 2 & 9 & 1 & 11 & 7 & 6 & 26 & 4 & 5 & 95 \\
\hline Potsdam & 1 & 1 & 6 & 0 & 2 & 0 & 0 & 1 & 1 & 0 & 0 & 12 \\
\hline Saintpaul & 31 & 27 & 22 & 12 & 5 & 8 & 22 & 23 & 24 & 11 & 11 & 196 \\
\hline Sandiego & 5 & 3 & 1 & 3 & 1 & 6 & 7 & 5 & 3 & 3 & 6 & 43 \\
\hline Senftenberg & 29 & 20 & 6 & 7 & 3 & 3 & 1 & 2 & 2 & 3 & 5 & 81 \\
\hline Stanley & 21 & 9 & 10 & 7 & 14 & 16 & 9 & 8 & 4 & 9 & 21 & 128 \\
\hline Thompson & 11 & 9 & 19 & 16 & 9 & 17 & 16 & 23 & 17 & 24 & 18 & 179 \\
\hline Typhi & 24 & 25 & 61 & 61 & 34 & 49 & 44 & 49 & 60 & 63 & 42 & 512 \\
\hline Typhimurium & 121 & 133 & 148 & 127 & 88 & 93 & 98 & 67 & 74 & 79 & 79 & 1107 \\
\hline Virchow & 1 & 4 & 5 & 3 & 4 & 41 & 4 & 2 & 1 & 3 & 8 & 76 \\
\hline Weltevreden & 1 & 6 & 1 & 4 & 2 & 0 & 1 & 0 & 2 & 3 & 4 & 24 \\
\hline
\end{tabular}

Additional serotypes reported every year can be found in the annual WA communicable disease surveillance reports (Department of Health).

Source: Washington State Department of Health.

meat products; so producers can attempt but are not required to control it. Salmonella spp. can grow as biofilms on common surfaces used to process food, including stainless steel. Cross-contamination may be one of the main obstacles in reducing the prevalence of these bacteria in restaurants and other food-processing establishments as sources of recurrent outbreaks in WA (CDC, 2008a, 2013; Paz-Mendez et al., 2017; Green et al., 2018). Several reports have highlighted the potential for various serotypes of $S$. enterica to grow within the phyllosphere of several food-producing plants when exposure to this pathogen occurs through the soil or irrigation water (Barak et al., 2008; Gu et al., 2011; Zheng et al., 2013; Haendiges et al., 2018). These characteristics make Salmonella outbreaks linked to produce categories likely to occur in the future. Travel abroad is another wellrecognized risk factor for salmonellosis (Ekdahl et al., 2005) as noted in this report. Contact with live poultry and amphibians was another common outbreak source in Wa- shington that is well-recognized as a risk factor (Woodward et al., 1997; Behravesh et al., 2014; Basler et al., 2016; Bosch et al., 2016; Ribas and Poonlaphdecha, 2017).

Several large outbreaks in WA have been linked to Salmonella contamination of foods. An outbreak in 2014 linked to eating a raw beef "kitfo" dish sickened over 40 people. Starting in 2007, peanut butter was recognized as a new vehicle for salmonellosis (Sheth et al., 2011). WA reported 27 ill from 2 nut butter outbreaks since 2007. In 2015 there was the largest pork-associated salmonellosis outbreak in WA history (CDC, 2015a; Kawakami et al., 2016). This multiclonal Salmonella outbreak was linked to whole hogs from a slaughter facility and resulted in a large pork recall. Slaughter facilities in the past have been recognized as the most important source of Salmonella contamination for Salmonellafree hogs (Swanenburg et al., 2001a, 2001b).

STEC infections acquired through foods remain a significant source of death and severe complications in WA. 
Table 3. Foods Associated with Clusters and Outbreaks in Washington 2007-2017

\begin{tabular}{|c|c|c|c|c|}
\hline $\begin{array}{l}\text { IFSAC } \\
\text { category }\end{array}$ & Etiology & Serotype(s) & $\begin{array}{l}\text { No. of } \\
\text { WA cases }\end{array}$ & $\begin{array}{l}\text { No. of } \\
\text { outbreaks }\end{array}$ \\
\hline Beef & $\begin{array}{l}\text { Escherichia coli, Shiga } \\
\text { toxin-producing }\end{array}$ & $\mathrm{O} 157: \mathrm{H} 7$ & 9 & 2 \\
\hline Beef & Salmonella enterica & Senftenberg, Typhimurium, Braenderup & 20 & 3 \\
\hline Chicken & S. enterica & Heidelberg, I 4,[5],12:i:- & 104 & 5 \\
\hline Dairy & $\begin{array}{l}\text { E. coli, Shiga } \\
\text { toxin-producing }\end{array}$ & O157:H7; O121, O26:H11, O157:NM(H-) & 18 & 5 \\
\hline Dairy & Listeria monocytogenes & & 20 & 5 \\
\hline Dairy & S. enterica & Dublin & 3 & 1 \\
\hline Eggs & S. enterica & Enteritidis, Typhimurium & 69 & 2 \\
\hline Fish & S. enterica & Paratyphi B var. L(+) tartrate + , Weltevreden & 1 & 1 \\
\hline Fruits & L. monocytogenes & & 1 & 1 \\
\hline Fruits & S. enterica & $\begin{array}{l}\text { I 4,[5],12:b:- var. L(+) tartrate +, Litchfield, } \\
\text { Panama, Agona, Braenderup, Worthington, } \\
\text { Enteritidis, Chailey, Infantis, Newport }\end{array}$ & 116 & 10 \\
\hline Grains_-beans & $\begin{array}{l}\text { E. coli, Shiga } \\
\text { toxin-producing }\end{array}$ & O121, O26:NM & 6 & 2 \\
\hline Herbs & S. enterica & Wandsworth, Typhimurium & 33 & 4 \\
\hline Nuts-seeds & $\begin{array}{l}\text { E. coli, Shiga } \\
\text { toxin-producing }\end{array}$ & $\mathrm{O} 157: \mathrm{H7}$ & 2 & 1 \\
\hline Nuts-seeds & S. enterica & $\begin{array}{l}\text { Typhimurium, Newport, Hartford, Oranienburg, } \\
\text { Gaminara, Montevideo, Seftenberg }\end{array}$ & 29 & 4 \\
\hline Oils-sugars & S. enterica & Virchow & 1 & 1 \\
\hline Other & S. enterica & $\begin{array}{l}\text { Heidelberg, I 4,[5],12:b:- var. L(+) tartrate +, } \\
\text { Javiana, Okatie, Thompson, Weltevreden }\end{array}$ & 16 & 1 \\
\hline Pork & S. enterica & Enteritidis, I 4,[5],12:i:-, Infantis & 215 & 5 \\
\hline $\begin{array}{l}\text { Seeded } \\
\text { vegetables }\end{array}$ & S. enterica & Saintpaul, Newport, Paratyphi B, Poona & 66 & 5 \\
\hline Sprouts & $\begin{array}{l}\text { E. coli, Shiga } \\
\text { toxin-producing }\end{array}$ & O26, 0121 & 12 & 2 \\
\hline Sprouts & S. enterica & $\begin{array}{l}\text { Typhimurium, Newport, Enteritidis, Muenchen, } \\
\text { Cubana, Kentucky }\end{array}$ & 34 & 4 \\
\hline Turkey & S. enterica & Subspecies IIIa, Hadar, I 4,[5],12:i:- & 12 & 3 \\
\hline $\begin{array}{l}\text { Vegetable } \\
\text { row crops }\end{array}$ & $\begin{array}{l}\text { E. coli, Shiga } \\
\text { toxin-producing }\end{array}$ & O157:H7, O157:NM (H-), O26 & 28 & 9 \\
\hline $\begin{array}{l}\text { Vegetable } \\
\text { row crops }\end{array}$ & S. enterica & Typhimurium, Javiana, Enteritidis & 30 & 3 \\
\hline Multiple & $\begin{array}{l}\text { E. coli, Shiga } \\
\text { toxin-producing }\end{array}$ & $\mathrm{O} 157: \mathrm{H} 7, \mathrm{O} 121$ & 79 & 6 \\
\hline Multiple & L. monocytogenes & & 5 & 3 \\
\hline Multiple & S. enterica & $\begin{array}{l}\text { IV 50:z4,z23:-, Typhimurium, Sandiego, I 4,[5],12:i:-, } \\
\text { Enteritidis, Muenchen, Newport, Chester, Anatum, } \\
\text { Heidelberg, Thompson, Paratyphi B var. L(+) tartrate + }\end{array}$ & 279 & 18 \\
\hline
\end{tabular}

${ }^{a}$ www.cdc.gov/foodsafety/ifsac/projects/food-categorization-scheme.html

Many of the STEC outbreaks (2007-2017) were associated with previously reported high-risk food vehicles particularly undercooked beef, raw sprouts, and unpasteurized milk (Erickson and Doyle, 2007; Neil et al., 2012; Luna-Gierke et al., 2014; Morton et al., 2017) in addition to flour, which has emerged as a risk factor for STEC infections in recent years (Morton et al., 2017). Animal exposures at petting zoos and state fairs are also a significant source of STEC infections. In 2015, WA reported an E. O157:H7 outbreak linked to attendance at a dairy education event. Environmental samples collected at the event site yielded PFGE patterns indistinguishable from the outbreak strain (Dunbar et al., 2015).

With the release of Shiga toxin EIA that allow clinical laboratories to better identify non-O157, there was a concomitant reduction in STEC culture submissions to WAPHL. In addition, with the emergence of polymerase chain reaction- based enteric testing, an increase in stool specimen submissions was noted (as opposed to isolate submissions). CIDT has impacted the workflow at WAPHL as specimen submissions have increased and isolate submissions have decreased. This trend is predicted to continue in future years. It will be important for the WAPHL to facilitate isolate recovery in future years as these new technologies expand and replace current testing workflows at clinical laboratories.

Listeriosis associated with ice cream, raw milk, and Mexican style soft cheeses was identified as a problem as early as 1985 and continues to this day (Linnan et al., 1988; Jackson et al., 2018). The ubiquity of L. monocytogenes in the environment and its potential to grow in biofilms mean that a previously unrecognized food vehicle could cause a foodborne outbreak (Ferreira et al., 2014). WA had two notable recurring listeriosis outbreaks from dairy products. 


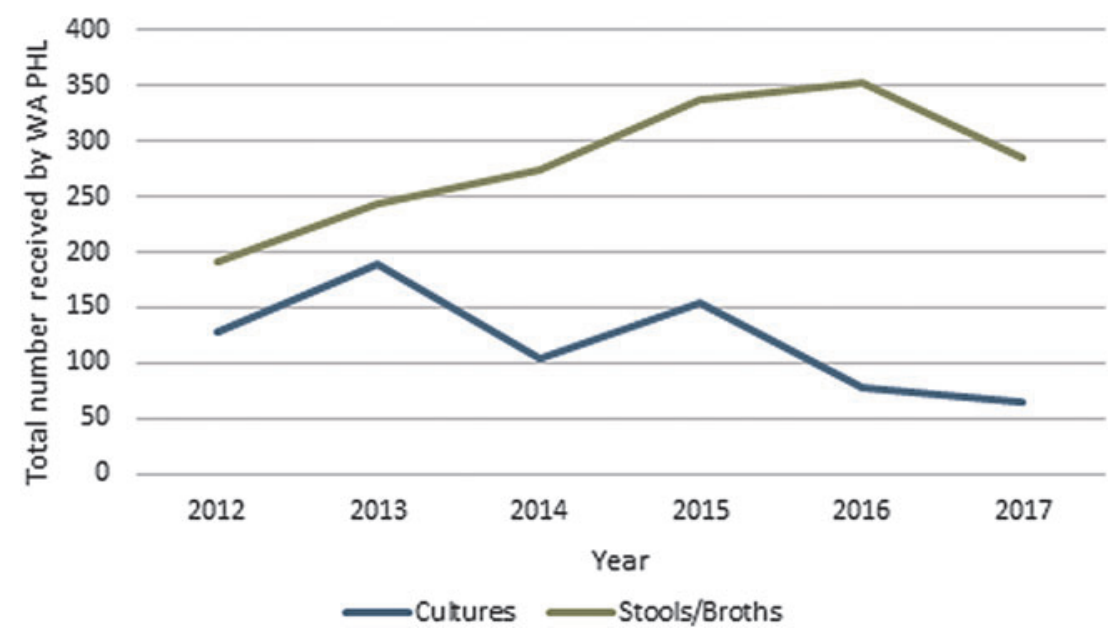

FIG. 2. Number of cultures and stools/broths received by WAPHL 2011-2017. WAPHL, Washington State Public Health Laboratories.

Two patients hospitalized at the same facility in 2014 2015 and one a year later in 2016 developed listeriosis found to be linked to pasteurized ice cream served at the facility and produced by a local company (Rietberg et al., 2016). Pasteurized soft Mexican cheese produced by a local firm sickened several people in 2010 and again in 2015. Sushi and frozen vegetables have also been linked to listeriosis outbreaks in WA.

The implementation of policies or campaigns to encourage the use of specific interventions, in addition to the implementation of better identification tools (on-site rapid testing, whole-genome sequencing), may lead to the reduction in the incidence of enteric infections. There is strong evidence indicating that in areas of the country where these infections are investigated, such as FoodNet sites, there has been a reduction (by 30\%) in illness incidence (Ailes et al., 2008). Better access to rapid test kits that can identify the presence of pathogens at food-processing facilities is also needed. Public health will, in the meantime, continue to rely on surveillance of notifiable conditions through the work of local health jurisdictions who conduct epidemiological and environment investigations. It is possible that the impact of the use of NGS tools may by overshadowed by the impact of CIDTs as fewer illnesses get characterized with an isolate culture that can then flow to get characterized by NGS. Nonetheless, NGS characterization offers unparalleled resolution in providing evidence to pathogen relatedness that will revolutionize the way foodborne disease investigations are conducted in the laboratory as PFGE is phased out.

To understand the impact of future laboratory testing as the use of NGS becomes more streamlined, it would be important for reference laboratories to track the amount of time it takes to detect clusters, number of outbreaks solved with food source identified, number of cases per cluster, and number of cases linked to a food source. In addition, there is work to be carried out to increase the proportion of stool samples submitted for laboratory testing for foodborne illnesses (Ailes et al., 2012) and in laboratory methodologies that ensure the recovery of an isolate. Characterization of isolates remains the key to a solved foodborne disease investigation (Hurd et al., 2012).

\section{Limitations}

Foodborne diseases attributed to botulism, norovirus, and yersiniosis were not evaluated. In addition, data for Campylobacter and Shigella are not complete as WAPHL did not test all the submitted isolates by PFGE. In WA the investigation of campylobacteriosis individual cases is considered optional (Washington State Department of Health, 2016).

Although the case counts were provided, most PHL data were missing vehicle source or cluster association data other than PFGE. All outbreaks and clusters reported herein were closed at the time of the writing of this article.

\section{Acknowledgments}

The authors thank the editing assistance of Bonnie Olsen and recognize all the work that several microbiologists have contributed to the Enterics, Food, Special Bacteriology Reference, and PFGE units of WAPHL. This work was supported in part by the Epidemiology and Laboratory Capacity grant sponsored by the CDC.

\section{Disclosure Statement}

No competing financial interests exist.

\section{References}

Ailes E, Demma L, Hurd S, et al. Continued decline in the incidence of Campylobacter infections, FoodNet 1996-2006. Foodborne Pathog Dis 2008;5:329-337.

Ailes E, Scallan E, Berkelman RL, Kleinbaum DG, Tauxe RV, Moe CL. Do differences in risk factors, medical care seeking, or medical practices explain the geographic variation in campylobacteriosis in Foodborne Diseases Active Surveillance Network (FoodNet) sites? Clin Infect Dis 2012; 54(Suppl 5):S464-S471.

Barak JD, Liang A, Narm KE. Differential attachment to and subsequent contamination of agricultural crops by Salmonella enterica. Appl Environ Microbiol 2008;74:5568-5570.

Barrett TJ, Gerner-Smidt P, Swaminathan B. Interpretation of pulsed-field gel electrophoresis patterns in foodborne disease investigations and surveillance. Foodborne Pathog Dis 2006; $3: 20-31$. 
Barton Behravesh C, Jones TF, Vugia DJ, et al. Deaths associated with bacterial pathogens transmitted commonly through food: Foodborne diseases active surveillance network (FoodNet), 1996-2005. J Infect Dis 2011;204:263-267.

Basler C, Nguyen TA, Anderson TC, Hancock T, Behravesh CB. Outbreaks of human Salmonella infections associated with live poultry, United States, 1990-2014. Emerg Infect Dis 2016;22:1705-1711.

Behravesh CB, Brinson D, Hopkins BA, Gomez TM. Backyard poultry flocks and salmonellosis: A recurring, yet preventable public health challenge. Clin Infect Dis 2014;58:1432-1438.

Bender JB, Hedberg CW, Boxrud DJ, et al. Use of molecular subtyping in surveillance for Salmonella enterica serotype Typhimurium. N Engl J Med 2001;344:189-195.

Bosch S, Tauxe RV, Behravesh CB. Turtle-associated salmonellosis, United States, 2006-2014. Emerg Infect Dis 2016; 22:1149-1155.

CDC. Multistate outbreak of Salmonella infections associated with frozen pot pies-United States, 2007. MMWR Morb Mortal Wkly Rep 2008a;57:1277-1280.

CDC. Outbreak of Salmonella serotype Saintpaul infections associated with multiple raw produce items-United States, 2008. MMWR Morb Mortal Wkly Rep 2008b;57: 929-934.

CDC. Multistate Outbreak of Human Salmonella Enteritidis Infections Linked to Alfalfa Sprouts and Spicy Sprouts (Final Update). Atlanta, GA: Centers for Disease Control and Prevention, 2011.

CDC. Outbreak of Salmonella Heidelberg infections linked to a single poultry producer-13 States, 2012-2013. MMWR Morb Mortal Wkly Rep 2013;62:553-556.

CDC. Foodborne Outbreak Online Database. Services U.S. Department of Human and Helath Services, ed. Atlanta, GA: Centers for Disease Control and Prevention, 2015a.

CDC. Size and Extent of Foodborne Outbreaks. Volume 2018, Atlanta, GA: Centers for Disease Control and Prevention, 2015b.

CDC. Listeria (Listeriosis)—Outcomes. Prevention. Atlanta, GA: Centers for Disease Control and Prevention, 2016a.

CDC. PulseNet Timeline. Volume 2018: Atlanta, GA: Centers for Disease Control and Prevention, 2016b.

de la Maza LM. Color Atlas of Medical Bacteriology. Washington, DC: ASM Press, 2004.

Dunbar SA, Ritchie VB, Hoffmeyer MR, Rana GS, Zhang H. Luminex $\left({ }^{\circledR}\right)$ multiplex bead suspension arrays for the detection and serotyping of Salmonella spp. Methods Mol Biol 2015;1225:1-27.

Ekdahl K, de Jong B, Wollin R, Andersson Y. Travel-associated non-typhoidal salmonellosis: Geographical and seasonal differences and serotype distribution. Clin Microbiol Infect 2005;11:138-144.

Erickson MC, Doyle MP. Food as a vehicle for transmission of Shiga toxin-producing Escherichia coli. J Food Prot 2007;70: 2426-2449.

Farber JM, Peterkin PI. Listeria monocytogenes, a food-borne pathogen. Microbiol Rev 1991;55:476-511.

FDA. Food: BAM: Detection and Enumeration of Listeria monocytogenes. Washington, DC: U.S. Food and Drug Administration, 2017.

Ferreira V, Wiedmann M, Teixeira P, Stasiewicz MJ. Listeria monocytogenes persistence in food-associated environments: Epidemiology, strain characteristics, and implications for public health. J Food Prot 2014;77:150-170.
Garcia LS, Isenberg HD. Clinical Microbiology Procedures Handbook. Washington, DC: ASM Press, 2010.

Graves LM, Swaminathan B. PulseNet standardized protocol for subtyping Listeria monocytogenes by macrorestriction and pulsed-field gel electrophoresis. Int $\mathbf{J}$ Food Microbiol 2001;65:55-62.

Green A, Defibaugh-Chavez S, Douris A, et al. Intensified sampling in response to a Salmonella Heidelberg outbreak associated with multiple establishments within a single poultry corporation. Foodborne Pathog Dis 2018;15:153160.

$\mathrm{Gu} \mathrm{G}, \mathrm{Hu}$ J, Cevallos-Cevallos JM, et al. Internal colonization of Salmonella enterica serovar Typhimurium in tomato plants. PLoS One 2011;6:e27340.

Haendiges J, Blessington T, Zheng J, Davidson G, Miller JD, Hoffmann M. Complete genome sequences of four Salmonella enterica subsp. enterica serovar Senftenberg and Montevideo isolates associated with a 2016 multistate outbreak in the United States. Genome Announc 2018;6(26): e00630.

Holt JG. Bergey's Manual of Determinative Bacteriology, 9th edition. Baltimore, MD: Lippincott Williams \& Wilkins, 1994.

Hurd S, Patrick M, Hatch J, et al. Clinical laboratory practices for the isolation and identification of Campylobacter in Foodborne Diseases Active Surveillance Network (FoodNet) sites: Baseline information for understanding changes in surveillance data. Clin Infect Dis 2012;54(Suppl 5):S440S445.

Jackson KA, Gould LH, Hunter JC, Kucerova Z, Jackson B. Listeriosis outbreaks associated with soft cheeses, United States, 1998-2014. Emerg Infect Dis 2018;24:1116-1118.

Jorgensen JH. Manual of Clinical Microbiology. Washington, DC: ASM Press, 2015.

Kawakami VM, Bottichio L, Angelo K, et al. Notes from the field: Outbreak of multidrug-resistant Salmonella infections linked to pork-Washington, 2015. MMWR Morb Mortal Wkly Rep 2016;65:379-381.

Laufer AS, Grass J, Holt K, Whichard JM, Griffin PM, Gould LH. Outbreaks of Salmonella infections attributed to beefUnited States, 1973-2011. Epidemiol Infect 2015;143:20032013.

Linnan MJ, Mascola L, Lou XD, et al. Epidemic listeriosis associated with Mexican-style cheese. N Engl J Med 1988; 319:823-828.

Luna-Gierke RE, Griffin PM, Gould LH, et al. Outbreaks of non-O157 Shiga toxin-producing Escherichia coli infection: USA. Epidemiol Infect 2014;142:2270-2280.

MacFaddin JF. Biochemical Tests for Identification of Medical Bacteria. Baltimore, MD: Lippincott Williams \& Wilkins, 2000.

Morton V, Cheng JM, Sharma D, Kearney A. An outbreak of Shiga toxin-producing Escherichia coli O121 infections associated with flour-Canada, 2016-2017. Can Commun Dis Rep 2017;43:154-155.

Neil KP, Biggerstaff G, MacDonald JK, et al. A novel vehicle for transmission of Escherichia coli O157:H7 to humans: Multistate outbreak of E. coli O157:H7 infections associated with consumption of ready-to-bake commercial prepackaged cookie dough-United States, 2009. Clin Infect Dis 2012;54: 511-518.

Parsons MB, Cooper KL, Kubota KA, et al. PulseNet USA standardized pulsed-field gel electrophoresis protocol for 
subtyping of Vibrio parahaemolyticus. Foodborne Pathog Dis 2007;4:285-292.

Paz-Mendez AM, Lamas A, Vazquez B, Miranda JM, Cepeda A, Franco CM. Effect of food residues in biofilm formation on stainless steel and polystyrene surfaces by Salmonella enterica strains isolated from poultry houses. Foods 2017;6:E106.

Ribas A, Poonlaphdecha S. Wild-caught and farm-reared amphibians are important reservoirs of Salmonella, a study in North-East Thailand. Zoonoses Public Health 2017;64:106110.

Ribot EM, Fair MA, Gautom R, et al. Standardization of pulsed-field gel electrophoresis protocols for the subtyping of Escherichia coli O157:H7, Salmonella, and Shigella for PulseNet. Foodborne Pathog Dis 2006;3:59-67.

Ribot EM, Fitzgerald C, Kubota K, Swaminathan B, Barrett TJ. Rapid pulsed-field gel electrophoresis protocol for subtyping of Campylobacter jejuni. J Clin Microbiol 2001;39:18891894.

Rietberg K, Lloyd J, Melius B, et al. Outbreak of Listeria monocytogenes infections linked to a pasteurized ice cream product served to hospitalized patients. Epidemiol Infect 2016;144:2728-2731.

Sheth AN, Hoekstra M, Patel N, et al. A national outbreak of Salmonella serotype Tennessee infections from contaminated peanut butter: A new food vehicle for salmonellosis in the United States. Clin Infect Dis 2011;53:356-362.

Staples M, Fang NX, Graham RM, Smith HV, Jennison AV. Evaluation of the SHIGA TOXIN QUIK CHEK and ImmunoCard STAT! EHEC as screening tools for the detection of Shiga toxin in fecal specimens. Diagn Microbiol Infect Dis 2017;87:95-99.

Stephenson J. New approaches for detecting and curtailing foodborne microbial infections. JAMA 1997;277:1337, 1339-1340.

Swaminathan B, Barrett TJ, Hunter SB, Tauxe RV. PulseNet: The molecular subtyping network for foodborne bacterial disease surveillance, United States. Emerg Infect Dis 2001;7: 382-389.

Swanenburg M, Berends BR, Urlings HA, Snijders JM, van Knapen F. Epidemiological investigations into the sources of Salmonella contamination of pork. Berl Munch Tierarztl Wochenschr 2001a;114:356-359.

Swanenburg M, van der Wolf PJ, Urlings HA, Snijders JM, van Knapen F. Salmonella in slaughter pigs: The effect of logistic slaughter procedures of pigs on the prevalence of Salmonella in pork. Int J Food Microbiol 2001b;70:231-242.

Tauxe RV. Molecular subtyping and the transformation of public health. Foodborne Pathog Dis 2006;3:4-8.

Washington State Department of Health. Annual Communicable Disease Reports. Volume 2018. Shoreline, WA: Washington State Department of Health.

Washington State Department of Health. Campylobacteriosis. Shoreline, WA: Washington State Department of Health, 2016.

Weyant RS. Identification of Unusual Pathogenic GramNegative Aerobic and Facultatively Anaerobic Bacteria. Baltimore, MD: Williams \& Wilkins, 1996.

Woodward DL, Khakhria R, Johnson WM. Human salmonellosis associated with exotic pets. J Clin Microbiol 1997;35: 2786-2790.

Zheng J, Allard S, Reynolds S, et al. Colonization and internalization of Salmonella enterica in tomato plants. Appl Environ Microbiol 2013;79:2494-2502.

Address correspondence to:

Ailyn C. Perez-Osorio, PhD

Public Health Laboratories

Washington State Department of Health 1610 N.E. 150th Street Shoreline, WA 98155

E-mail: ailyn.perez-osorio@doh.wa.gov 